\title{
Simulation and technical comparison of different wind turbine power control systems
}

\author{
Mojtaba Tahani ${ }^{1}$, Iman Rahbari ${ }^{2, *}$, Samira Memarian ${ }^{2}$, Saeedeh Mirmahdian ${ }^{3}$ \\ ${ }^{1}$ Iran University of Science and Technology, Tehran, Iran \\ ${ }^{2}$ Semnan University, Semnan, Iran \\ ${ }^{3}$ Islamic Azad University of Arak, Arak, Iran \\ * Corresponding author. Tel: +989128021976,E-mail: rahbarii2@asme.org
}

\begin{abstract}
: wind as a significant renewable source of energy along with different ways for its optimum utilization is attended. At this paper, initially different types of wind turbine power control systems are introduced briefly, then advantages and disadvantages of them, are evaluated in practical and theoretical aspects. At the following, governing generated power formulation is proved briefly, then the effective parameters on power, e.g. wind velocity, wind temperature are studied and simulated in MATLAB software. Then practical data from an actual stall control wind turbine entered and related curves are investigated. Based on these data, performance of an actual pitch control wind turbine is estimated and related curves are investigated. At the following, using Weibull theory, real power-time curve and estimated power-time curve, monthly produced energy of turbines are estimated. And finally Specific Power Performance (SPP) is defined and shown that pitch control system produced energy more than stall control system at the same rotor swept area.
\end{abstract}

Keywords: Wind Turbine, Power Control System, Pitch Control, Stall Control

\section{Introduction}

The human progresses in various scientific and industrial fields have increased the need to generate energy and to investigate its various resources. Providing this energy from fossil sources like oil and gas is not reasonable because of various reasons such as environmental pollutions, reduction of reservoir of these resources and the next generation's requirements for them. These facts along with economic problems and the increment of fuel cost have encouraged the researchers in various countries to pay more attention to renewable energies. Therefore, the wind, as one of the renewable energy resources, and its optimal exploitation methods, have been noticed so that the predictions indicate that in 2020 the portion of wind in generating the energy required for human activities will be more than $375 \mathrm{TWh}$. The design of wind turbines depends on the conditions of the location they are installed, and most of them are designed to generate power with the minimum possible cost at low wind speeds. Thus, if the wind speed exceeds a specified limit, some of the important parts of turbine may be harmed. The designers use various control systems to prevent these harms and also to optimal exploitation of turbines. The most important control systems are stall control, pitch control, and yaw control, from which the pitch control is the most common system [1 to 3] .

Of course, some researches were also performed to design other control systems. One of them is "control of wind turbine using memory based method" by Song [4]. Using this method, the turbine chooses the optimal power control method based on the previous experienced conditions. Another new method was also presented in the paper titled as "multi variable control strategy for variable speed variable pitch" by Bakhezzar et al. [5] . Using the doubly fed induction generator to control the voltage induced by rotor in the generator has been noticed by the researchers in the recent years. Fernandez and Garcia investigated this subject in a paper titled as "comparative study on doubly fed induction generator (DFIG) wind turbines operating with power regulation" [6] . Modeling and controlling this type of generators were performed by Hee Song Ko [7] . 
In this paper, the control systems of wind turbines were investigated comprehensively. In addition to theoretical facts, technical and empirical points were also involved. Furthermore, the power generated by different control systems was compared in this study. The effect of local conditions of the place considered for installing the turbine, such as wind blowing conditions, on the selection of the appropriate control system was also discussed in this paper.

\section{Investigation of generated power}

The one-dimensional BEM theory was used to investigate the power generation of wind turbines [3] . Based on this theory, the rotor of wind turbine can be modeled as an ideal impenetrable disk. Because there is no friction between air and the rotor, and the wake flow speed has no rotational component. The shape of stream lines thorough the rotor will be similar to figure (1). This disk decreases the speed from $\mathrm{V}_{0}$ at the upstream to $\mathrm{u}$ at the rotor plate, and to $\mathrm{u}_{1}$ at the back of rotor. At normal speeds, the flow can be assumed incompressible, and the speed and pressure variations can be assumed as shown in figure (1) .

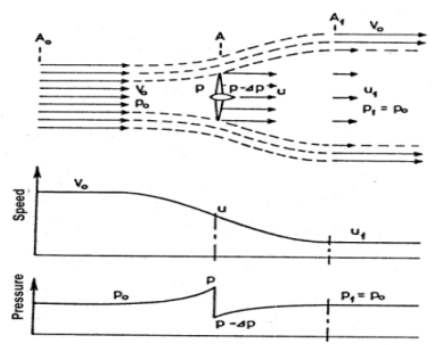

Fig. 1. Demonstration of streamlines, axial speed and pressure up- downstream of rotor.

Using axial momentum equation, it can be proved that:

$u=\frac{1}{2}\left(V_{0}+u_{2}\right)$

Also, the usable power in a cross section area equal to the area swept by rotor (A) is:

$$
P_{\text {avail }}=\frac{1}{2} \rho A V_{0}^{3}
$$

The dimensionless power coefficient is obtained by dividing the power by the usable power:

$C_{P}=\frac{P}{\frac{1}{2} \rho V_{0}^{3} A}$

And finally, the induction factor is defined as:

$u=(1-a) V_{0}$

It can be observed that for $a=1 / 3, C_{P, \max }=16 / 27$. 


\section{Investigation of power control systems}

\subsection{Stall control systems}

Blade design of this type of turbines is so that they naturally control the power generated by turbine. These rotors with constant pitch are designed to operate near the optimal tip speed in moderate winds. In turbines with this type of control system, an asynchronous generator is often used by which the rotor rotational speed is kept approximately constant. A rotating tip located at the end of the rotor is usually used as the aerodynamic brake. This device which is activated by centrifugal force, is subjected against the wind flow with a $90^{\circ}$ angle, and limits the rotor momentum by applying the opposite torque due to the drag force.

\subsection{Pitch control systems}

In a turbine with pitch control system, all blades can rotate about the root, and thus, the attack angle changes simultaneously throughout the rotor length. One of the most conventional mechanical mechanisms of the rotor pitch control contains a piston inserted inside the turbine main shaft. This piston changes the rotor pitch by its reciprocating movement using a mechanism installed forward the turbine hub. Obviously, the lift coefficient has a direct relation with the attack angle [1]. Therefore, decreasing the attack angle reduces the lift force and the power. Thus, pitch control system can control the output power by rotating the rotors. Also, referring the power curve of this type of turbines, it is obviously found that since the rotors can rotate slowly, the power curve is smoother and the power peaks are reduced [3] . To overcome the problem caused by great peaks in power for high speeds in a wind turbine with pitch control system, a system named as "OptiSlip" produced by Vestas was used.

From technical point of view, using pitch control mechanisms to control power necessitates the use of very strong hydraulic systems to generate and transfer very high pressures (120 Bar for medium wind turbines, and even more for greater turbines). Providing this hydraulic system affects the turbine total price. In places with high air turbulence, the pitch control system should operate harder. This results in overheating the hydraulic oil, and finally, lengthy turbine stops by safety system. This reduces the turbine productivity.

\subsection{Active stall control systems}

There is another method which uses the combination of pitch and stall control systems. In this system, to achieve the maximum efficiency at low wind speeds the rotors are repositioned like a wind turbine controlled by pitch. At high speeds, the rotors are rotated slowly against the wind to get stall. With this type of control, a smoother limited power is achieved compared with pitch control turbines. Combining both systems facilitates the required stops in emergency cases and restarting wind turbines compared with stall control. This type of system is less common today [2] .

\subsection{Yaw control systems}

In this control system, instead of limiting the output power using pitch or stall controls, the turbine yaw is controlled. The machines which use pitch and stall control systems usually have yaw control. This system receives the data related to wind flow direction from the turbine wind gauge and tries to turn the nacelle so that the maximum air flow rate enters the rotor disk. In a machine controlled by yaw system, at high wind speeds, the rotor turns against the wind direction to reduce the air flow rate in rotor, and thus, the generated power decreases. 


\section{Study procedure}

\subsection{Weibull distribution method theory and its application in estimating the available wind electricity energy generation}

Considering the random nature of wind with long-term measurements in various time periods, Weibull Density Function was used to compute the wind energy [8] .

$$
F(V)=\frac{k}{C}\left(\frac{V}{C}\right)^{k-1} e^{-\left(\frac{V}{c}\right)^{k}}
$$

F (v), the cumulative distribution function, is:

$$
F(V)=1-e^{-\left(\frac{V}{c}\right)^{k}}
$$

Where $\mathrm{V}$ is the wind speed, c and $\mathrm{k}$ are scale parameter and shape parameter, respectively. These parameters can be computed using "Maximum likelihood" method with iteration from the following equations:

$$
\begin{aligned}
& k=\left(\frac{\sum_{i=1}^{n} V_{i}^{k} \operatorname{Ln}\left(V_{i}\right)}{\sum_{i=1}^{n} V_{i}^{k}}-\frac{\sum_{i=1}^{n} \operatorname{Ln}\left(V_{i}\right)}{n}\right)^{-1} \\
& C=\left(\frac{1}{n} \sum_{i=1}^{n} V_{i}^{k}\right)^{\frac{1}{k}}
\end{aligned}
$$

Where $V_{i}$, is the speed at time period $i$ and $n$ is the number of the wind non-zero speeds. The continuous distribution of wind flow in the studied region is obtained using Weibull curve. The generated energy is estimated by combining this curve and the power curve of wind turbines. The energy of a wind turbine in a month is investigated by following equations:

$$
E_{\text {Month }}=N_{0} \int_{V_{\text {Cut-In }}}^{V_{\text {Cut-Out }}} P(u) f(u) d u
$$

Where $\mathrm{N}_{0}$ is 744 hours/month, $\mathrm{f}(\mathrm{u})$ is Weibull function and $\mathrm{P}(\mathrm{u})$ is power curve.

\subsection{Location of study}

Location of the present study was Paskulan wind farm in Manjil, a city in Iran. Its pressure can be assumed about 1 Atmosphere with a good precision. The average air temperature during the test period was $13.67^{\circ} \mathrm{C}$. Therefore, the average air density was $1.231 \mathrm{~kg} / \mathrm{m}^{3}$.

\subsection{Wind blow condition}

Since the wind patterns of a region repeat annually, the Weibull curve obtained in March 2003 [9] can be used to estimate the wind condition in March 2009 with a good accuracy. Based on this curve, weibull shape parameter $(\mathrm{k})$ was 1.68 , weibull scale parameter (A) was $11.7 \mathrm{~m} / \mathrm{s}$ and average wind velocity was $10.4 \mathrm{~m} / \mathrm{s}$. As mentioned before, stall and pitch control 
systems are more applicable compared with the other control systems. Thus, in the following was concentrated on the sample turbines with these two control system types.

First, based on Eq. (3), the effective parameters on the power generated by turbine considering the weather conditions of the studied region were simulated in MATLAB software for two turbines with different control systems.

The first turbine is of $550 \mathrm{~kW}$ type and was made by NEG-MICON Company. It uses stall control system. The second turbine is of V47-660 kW type and was made by Vestas Company. It uses pitch control system and is equipped with OptiSlip. The power curves of above turbines for the ideal case and for the air conditions of the mentioned wind farm were shown in figures (2).

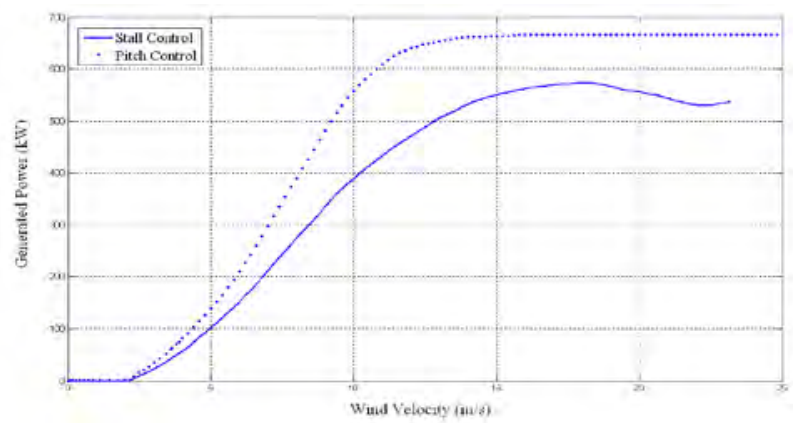

Fig. 2. Ideal power curve wind turbines.

For $550 \mathrm{~kW}$ wind turbine, it's obvious that maximum generated power, is $550 \mathrm{KW}$ occurs at $18 \mathrm{~m} / \mathrm{s}$. Power curve after reaching to maximum point, will be decreased. In the following, this curve will be compared with practical curve. For $660 \mathrm{~kW}$ wind turbine, it can be obviously observed that the power generated by the turbine is uniform compared with the past and remains constant after reaching the maximum value. This maximum power value occurs at speed of $15 \mathrm{~m} / \mathrm{s}$.

In the following, the power generated by $550 \mathrm{~kW}$ turbine is investigated in the real mode. The values used in this section were recorded by the logger located on these turbines. This system measures and records the turbine generated power data, wind speed, wind temperature, and some other parameters with 10 minute time intervals, And during the studied time period 4463 time intervals were recorded that, the turbine was active only during 1501 intervals. During the other intervals, the turbine was in stop mode due to maintenance and blowing wind with very high speeds (cut-out), or other unforeseen characters. In figure (3), the real generated power was shown versus the active times.

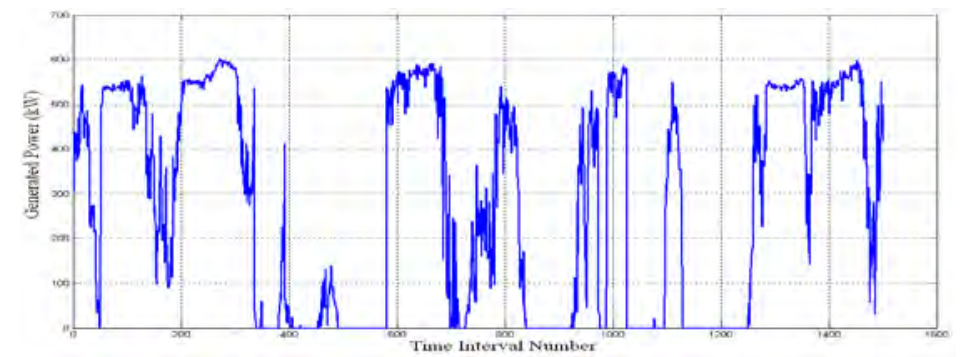

Fig. 3. Demonstration of Power vs. Time intervals for stall control wind turbine in real mode.

The power curve for active time intervals was shown in figure (4). 


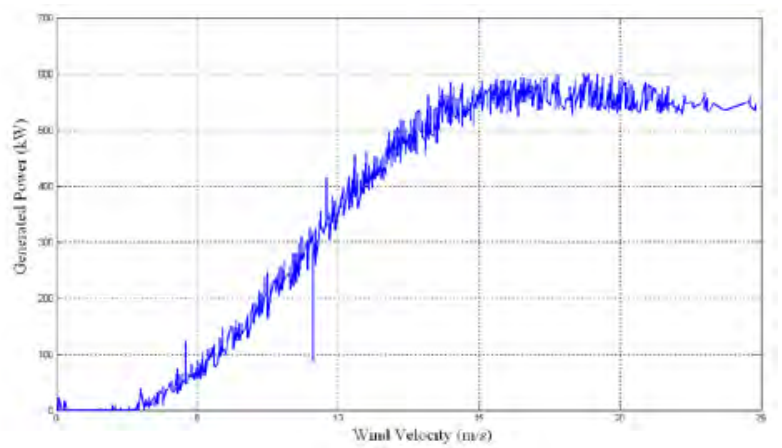

Fig. 4. Demonstration of Power curve for stall control wind turbine in real mode.

Comparing figures (2) and (4) reveals that there is a marked difference between the power generated in real mode and the power computed in ideal mode obtained with constant power values presented by the manufacturer and based on the weather conditions of the studied location.

The reason of this difference is that the turbine characteristics presented by the manufacturer (such as power coefficient and power curve based on standard DIN ISO 2533) are related to the generated power of $550 \mathrm{~kW}$, but in fact, the turbine maximum mechanical power is 600 $\mathrm{kW}$ (about 10\% more than the nominal power), and it was observed that with turbine optimum operation, this maximum value of power is exploitable.

The percentage error curve versus the wind speed was shown in figure (5).

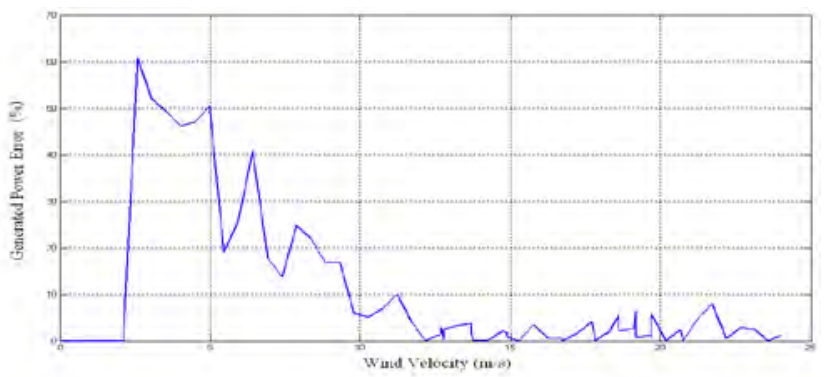

Fig. 5. The percentage error curve versus the wind speed for stall control wind turbine.

As shown in this figure, at speeds lower than $2.5 \mathrm{~m} / \mathrm{s}$ the turbine does not start to operation to generate remarkable power, thus, there is no percentage error. At near cut-in speeds, the percentage error is very high. The reason is the small value of generated power; therefore, it's not noticeable. It can be observed that the percentage error reduces with increasing speed and remains lower than $10 \%$ after the speed of $10 \mathrm{~m} / \mathrm{s}$.

Based on equation (9) and using trapezoidal numerical integrating method for the studied time period, $224110 \mathrm{kWh}$ of energy generation was estimated.

By computing the area under the power-real time curve by trapezoidal numerical integrating method, the real power generated during this time period reached $68672.9 \mathrm{kWh}$. Considering the fact that turbine was active only in $1 / 3$ of the time period, if assumed the turbine will operate in such a way this time interval, estimated energy using this method and Weibull function has $9.758 \%$ variations. Now assume the pitch regulated turbine installed in the previous location and subjected to the previous wind conditions. Assuming that the turbine 
stop time, due to periodical repairs or possible malfunctions and not generating power at speeds more than cut-in value, is equal to the corresponding value of stall controlled turbine, and the turbine operates in ideal conditions, the power-time curve of this turbine was estimated by figure (6).

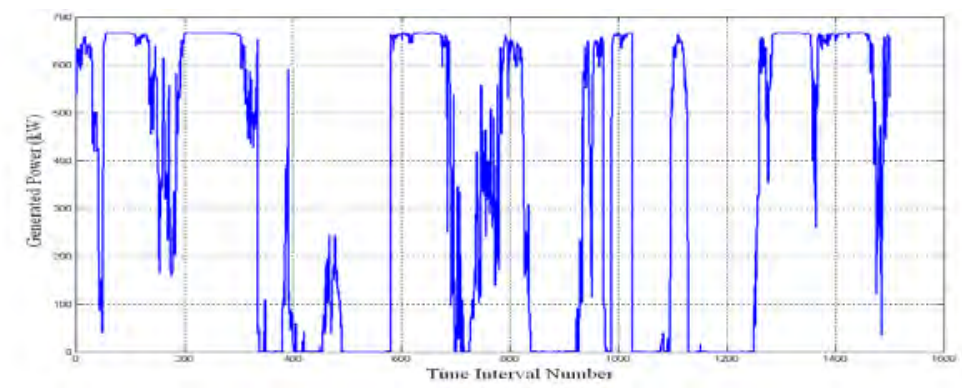

Fig. 6. Estimated Power Vs. Time intervals for pitch control wind turbine.

Comparing figures (6) and (3) obviously reveals that the variations of the power generated by pitch controlled turbine are very smaller than the corresponding values of stall controlled turbine. By numerical integrating in this period, it was found that $90670 \mathrm{kWh}$ of energy is exploitable from this turbine.

Based on Weibull theory and using equation (6) and trapezoidal numerical integrating method for the studied time period, $299690 \mathrm{kWh}$ of energy generation was estimated.

Considering the fact that the turbine was active during 1/3 of the period, the estimated value by Weibull theory has a good consistency with the value estimated using power curve. If assumed the turbine will operate in such a way this time interval, estimated energy using this method and Weibull function has $11.1634 \%$ variations.

By defining Specific Power Performance (SPP) as follows, the value of this parameter for pitch controlled and stall controlled turbines were presented in table (1).

$$
S P P=\frac{\text { Generated Energy }(K w h)}{\text { Rotor Swept Area } \quad\left(m^{2}\right)}
$$

Table 1. Specific Power Performance for various turbines

\begin{tabular}{llll}
\hline $\begin{array}{l}\text { Type of Power } \\
\text { Control system }\end{array}$ & Rotor Swept Area & $\begin{array}{l}\text { SPP based on } \\
\text { Weibull function }\end{array}$ & $\begin{array}{l}\text { SPP based on power- } \\
\text { time curve }\end{array}$ \\
\hline Stall Control & $1325 \mathrm{~m}^{2}$ & 169.13 & 154.1 \\
Pitch Control & $1735 \mathrm{~m}^{2}$ & 172.73 & 155.38 \\
\hline
\end{tabular}

As it can be observed, the value of Specific Power Performance for wind turbines using pitch control system is about $0.8-2.13 \%$ greater than the corresponding value of the wind turbines using stall control system.

\section{Conclusion}

In this study, the governing generated power formulation was first proved. Then, the types of power control systems were investigated theoretically and practically. It was found that selecting the appropriate power control system for optimum exploitation of turbine depends on the conditions of the intended location to install the turbine. It's possible that using pitch 
control system results in turbine failures due to the numerous times of operation; and thus, it reduces the turbine efficiency. Then, Weibull theory for estimating the energy generated by turbine was introduced and investigated. Then, power curves of two different wind turbines under the wind conditions of the studied region sketched using MATLAB. Then, the practical values of energy and power generated by stall controlled turbine were obtained and investigated based on the data received from the turbine installed in the region. Then, the power and energy generated by pitch controlled turbine were estimated. Finally, by defining Specific Power Performance and comparing two different control systems, it was found that SPP Value for pitch controlled turbine is about $0.8-2.13 \%$ greater than the corresponding value of stall controlled turbine. In choosing the appropriate wind turbine for installation in a site, this low difference along with more prices also should be considered.

\section{References}

[1] Erich Hau, Wind turbines, fundamentals, technologies, applications, economics, Springer, $2^{\text {nd }}$ Edition, 2005, pp. $73-88$.

[2] Thomas Ackermann, Wind power in power system, John Wiley and Sons, 2005, pp. 1320.

[3] Martin O. L. Hansen, Aerodynamics of wind turbine, EarthScan, 2008, pp. 39 - 48.

[4] Y. D. Song, Control of wind turbines using memory based method, journal of wind engineering and industrial aerodynamics 85, 2000, pp. 263-275.

[5] B. Boukhezzar, L. Lupu, H.Siguerdidjane, M. Hand, Multivariable control strategy for variable speed variable pitch wind turbine, Renewable energy journal 32, 2007, pp. 12731287.

[6] L. M. Fernandez, C. A. Garcia, Comparative study on performance of control systems for doubly fed induction generator (DFIG) wind turbines operating with power regulation, Energy journal 33, 2008, pp. 1438 - 1452.

[7] Hee - Song Ko, Gi- Gab Yoon, Won Pyo Hong, Modeling and control of a DFIG based variable speed wind turbine, Electric power research 78, pp. 1841 - 1849.

[8] Eyad S. Hrayshat, Wind availability and its potentials for electricity generation in Ta. la, Jordan, Renewable and Sustainable Energy Reviews Journal 9, 2005, pp. 111- 117.

[9] M. Sharifi, Application of Weibull function in estimation of produced energy by wind turbines in Iran, Proceedings of $21^{\text {st }}$ International Power System Conference 2003, 21902197. 